\title{
Ultrasound guided brachial plexus block can be advantageous in patients with avulsion type upper extremity injuries
}

\author{
İnan AYSEL, ${ }^{1}$ İsmet TOPÇU, ${ }^{2}$ Fatma Filiz KURT'
}

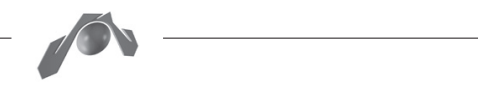

The ultrasound use for peripheral nerve blocks in regional anesthesia, since it provides synchronized view of the nerve, the syringe and the distribution of the local anesthetic, is a valuable method. ${ }^{[1,2]}$ Since the avulsion type upper extremity injures accompany brachial plexus (BP) damage, ultrasound-guided (US) method becomes more valuable. ${ }^{[3]}$

Due to a crush injury, a 25-year-old male patient applied to our hospital on the 5th hour of the injury, with subtotal amputation at the proximal aspect of the left arm. When the medical exam revealed the loss of sense and circulation in the arm, the patient was immediately received into operation. Since the case was ASA I, hemodynamically stable and showing no other trauma, a US guided regional anesthesia to supraclavicular brachial plexus block (BPB) and its catheterization was planned. In the operating room, the patient under standard monitoring received $1.5 \mathrm{mg}$ midazolam, $5 \mathrm{mcg}$ sufentanil, and nasal oxygen $2 \mathrm{~L} / \mathrm{min}$. During the US scan for block, BP image could not be observed, and there was a hematoma. The situation was verified with the comparison of the counter-part, so the anesthesia plan was replaced with endotracheal general anesthesia (Figure 1a, b).

Surgical exploration revealed all the roots of T1, C7, C8 roots were totally avulse, C6 root had a healthy image, $n$. axillaris and $n$. thoracodorsalis were responsive to neurostimulation (Figure 2). During surgery debridement and cannulation perfusion provided extremity perfusion, the fracture was treated with plate fixation, the arterial and venous injuries were
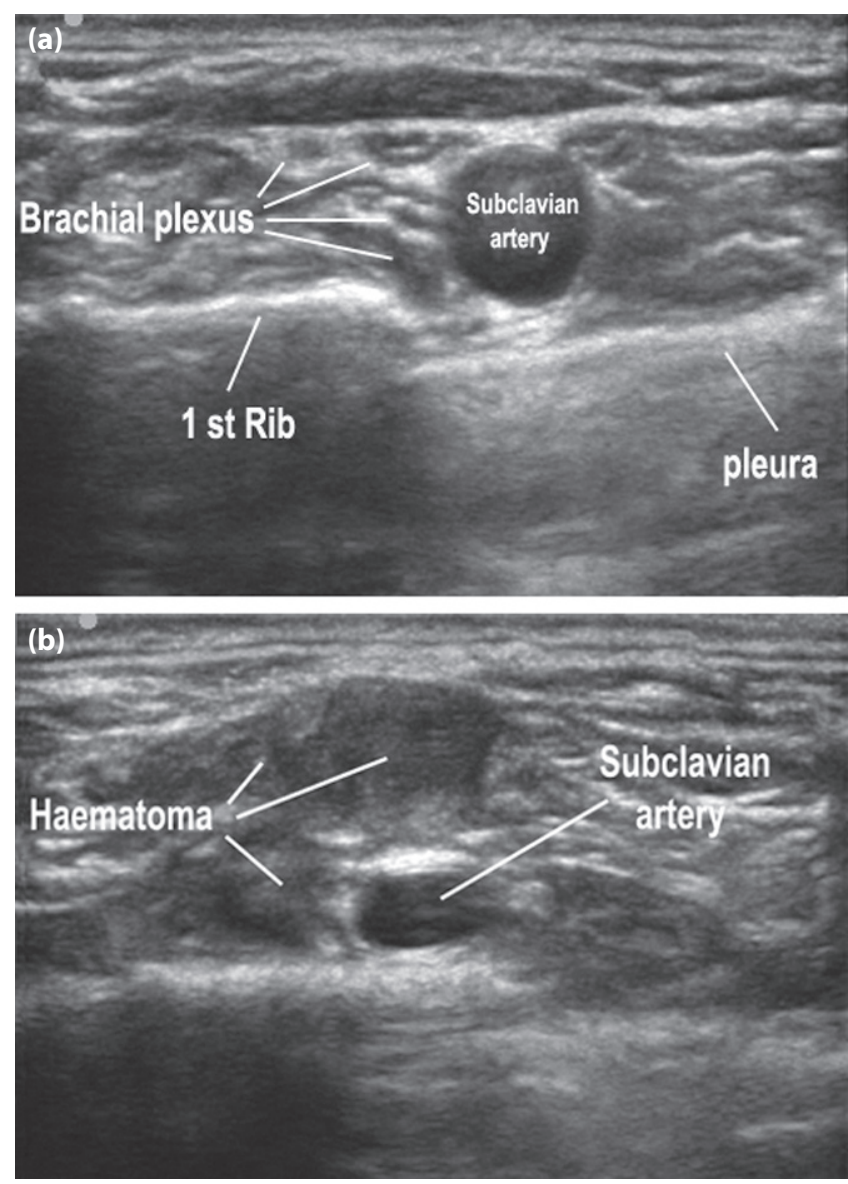

Figure 1.(a) Opposite side, US image of normal anatomy. (b) Wounded side, US image; cords of the brachial plexus are lacking, instead, subclavian artery seems to be compressed with the haematoma.

\footnotetext{
'Department of Anesthesiology and Intensive Care, Hand Microsurgery Orthopedics and Traumatology Hospital, Izmir;

${ }_{2}^{2}$ Celal Bayar Üniversitesi Tıp Fakültesi, Anesteziyoloji ve Yoğun Bakım Anabilim Dalı, Manisa, Turkey
}

Submitted (Başvuru tarihi) 03.07.2012 Accepted after revision (Düzeltme sonrası kabul tarihi) 13.09.2012

Correspondence (İletişim): Dr. İsmet Topçu. Güzelyurt Mahallesi, Tarzan Bulvarı, No: 88, Öncü Sitesi, 45030 Manisa, Turkey.

Tel: +90 - 236 - 2360330 / 1006 e-mail (e-posta): topcuismet@yahoo.com 


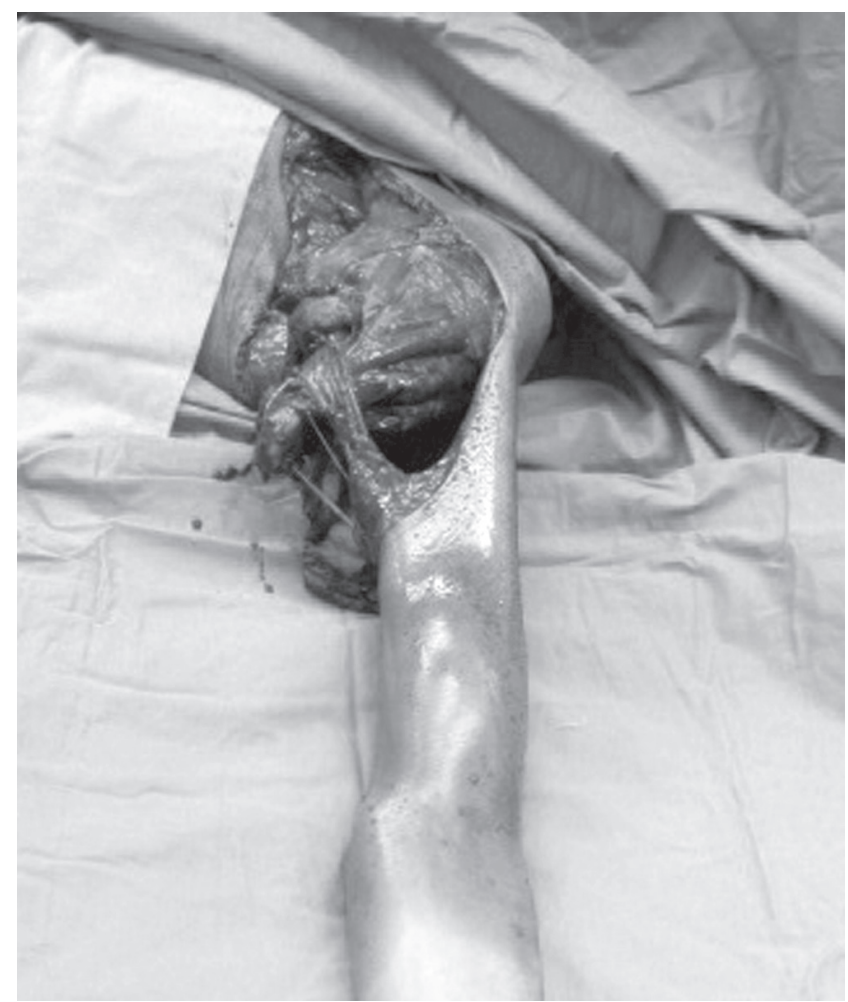

Figure 2. Intraoperative image of avulsion type brachial plexus injury.

treated with an end-to-end anastomosis, and the patient received neurotization of $\mathrm{n}$. medianus and n. ulnaris, from the proximal aspect of n.axillaris, n. radialis. Avulsion type BP damage indicates that the injury was caused by a propeller, but not being able shred the patient's clothes wholly, the propeller movement resulted in traction of plexus.

Neurostimulation guidance (NS) and US guidance are common methods for BPB. We are using both techniques individually or together. In this case US complemented BP blockage, and protected the patient from an unnecessary surgery, since plexus was unavailable for imaging from the supraclavicular aspect. If only NS was used, there would be potential complications like the waste of precious time, failure during surgery, and an altogether failing surgery. In this case, what prevented the patient from an unnecessary surgery was our inability to image the plexus from the supraclavicular aspect. Yet, even following avulsion type injuries the plexus should have been visible from this aspect. We suggest that the presence of hematoma should remind a plexus injury, and thus surgery should be avoided.

In conclusion, there can be BP injuries in avulsion type injuries with subtotal or total amputation proximal to the upper extremity, US-guided BPB could be more beneficial in comparison with NS guided $\mathrm{BPB}$.

Conflict-of-interest issues regarding the authorship or article: None declared.

\section{Peer-review: Externally peer-reviewed.}

\section{References}

1. Kapral S, Krafft P, Eibenberger K, Fitzgerald R, Gosch M, Weinstabl C. Ultrasound-guided supraclavicular approach for regional anesthesia of the brachial plexus. Anesth Analg 1994;78(3):507-13.

2. Sinha SK, Abrams JH, Weller RS. Ultrasound-guided interscalene needle placement produces successful anesthesia regardless of motor stimulation above or below $0.5 \mathrm{~mA}$. Anesth Analg 2007;105(3):848-52.

3. Kaiser R, Waldauf $P$, Haninec P. Types and severity of operated supraclavicular brachial plexus injuries caused by traffic accidents. Acta Neurochir (Wien) 2012;154(7):1293-7. 